\title{
Leadership styles in Kosovo businesses
}

Prof. Ass. Dr. Aziz Rexhepi, Prof. Ass. Dr. Hysen Sogojeva, Masc. Besarta Rexhepi, Prof. Ass. Dr.Bislim Lekiqi

University of Applied Sciences in Ferizaj, St. Universiteti, p.n. 70000 Ferizaj, Republic of Kosovo. aziz.rexhepi@ushaf.net

\begin{abstract}
It has often been said that the style of decision making is reflective of leadership style. Numerous studies in the field of management and leadership show that decision making style is a key factor contributing to the success of managers and organizational performance. In Kosovo, decision-making styles are conditioned by many factors. It should be noted that the most important factor in adequately matching the characteristics and knowledge of workers and the specifics required at work lies in the high number of unemployment. This often causes the workforce to perform work for which there is no professional training in the field. Also, from the research we found that there is a difference in the decision making style and the adaptation of the characteristics of work and employees between sectors. In general, the public sector tends to have more security for employees in the workplace, which drives them to look for other jobs, but the private sector shows more willingness to take risks. The difference also lies in the nature and activity of the work between the sectors studied. Often there are different approaches of employees and leaders between the banking sector or design organizations. Our study, which is based on empirical data, will present facts on decision-making styles, and factors that influence the determination or adaptation / non-adaptation of employees to the jobs in the sectors studied.
\end{abstract}

Keywords: style, decision making, intuitive, alert, manager. 


\section{Description}

Decision-making is an important process and can be considered as the process that results in choosing a belief or a course of action among several alternatives. Every decision-making process produces a final choice and important information.

The styles used by the individual influence the quality of the decision. Scott S. and Bruce (1995) have identified five different styles that can be used by the individual during the decision-making process. These are: rational, intuitive, addictive, spontaneous, and avoidant styles. In a rational style, decisionmaking is based on contemporary logical goals. In intuitive style, intuition and emotions have an effect on decision making. In a dependent style, the support and guidance of others is dominant in decisionmaking. In spontaneous style, unexpected and immediate decisions, without much thought, are more prominent, whereas in avoidant style, a decision-making evasion or a continuous delay is discussed (Scott S \& Bruce, 1995). (Kuzgun, 1992), on the other hand, defines decision making styles as intuitive, logical, dependent and indecisive. In the intuitive style, the individual believes that his feelings will lead to the right outcome and is aimed at a pleasant opportunity. In the addictive style, the individual believes in the beliefs of others. In a logical style, the individual analyses the options carefully and evaluates the positive and negative aspects of each option. In the indecisive style, the individual is not satisfied and every decision will change the decisions already made.

In today's modern management knowledge framework, importance is placed on collaboration among organizations, responsibility sharing is encouraged, and employees are involved in decision-making processes (Costa, Roe, \& Taillieu, 2001).

(Robinson, 1996) divides the management style into four categories: autocratic, paternalistic, democratic, and laissez-faire.

A number of decision-making styles have also been found that have a great impact on different aspects of the working relationship within the organization.

Decision-making styles are divided into analytical, conceptual, directive, and behavioral categories (Verma, 2009).

\section{Purpose}

The main purpose of this paper is to contribute to process improvement and the impact of decisionmaking style on business performance, by studying the impact of organizational behavior and human resource motivation on SMEs in Kosovo. 


\section{Methodology}

The study was conducted over a six-month period (2019) in Kosovo and in the Ferizaj Region. With the exception of some details of the analysis, the research method was designed to address the initial focus of the study, which was to explore the impact of motivation on decision making in Kosovo. Contemporary literature, empirical studies have been used for this purpose. as well as the experiences of transition and developed countries. The methodology used is in function of the goals set in this study. For the analysis of the results of the collected questionnaires, various statistical methods such as descriptive data analysis, analysis of variance (ANOVA), multiple regression, and other statistical tests were used.

Data were processed through SPSS (Statistical Package for Social Sciences).

Two hypotheses have been raised:

Hypothesis 1: In the company environment the dominant style is the vigilant decision making style Hypothesis 2: There is a very close relationship between decision making style and company performance.

Research articles:

1. Do you consult with your colleagues when you make an important decision?

2. I expect the work to be done well by the workers

3. I reward employees for the work they do in various ways and I constantly consult with them.

\section{The result of the study}

Hypothesis 1: In the company environment the prevailing style is the vigilant style

The environment surrounding a company is very important for its performance. According to (Beach $\&$ Connolly, 2005) the intuitive decision-making process is driven by feelings related to the situation and the environment in which it is located. This model includes a) humor b) remorse and frustration in making choices, c) belief and d) feelings of risk. And the rational model assumes that all decision makers have: a) unlimited information, b) skills that they use efficiently c) they know all the possibilities and consequences d) they believe that optimal actions will be logically discovered. As Kosovo gets involved in countries with a collectivist culture, we will see how different elements of this culture or the environment that surround it appear in decision making. The whole analysis was conducted taking into account the five decision-making styles highlighted by (Deniz, 2004), which are: alert, avoidant, hypervigilant, supportive and impulsive. 
The hypothesis is that the managers of the companies interviewed in the Ferizaj / Uroizevac region have a vigilant style, which means they analyze all the possible options before making a decision. We were prompted for this by our visits to these companies, where the existence of a very vigilant environment was noted. This was also clearly distinguished from the analysis that managers made of every process that surrounded them. But the alert aspect also stood out in the way they controlled their employees. This style was analyzed considering the culture and various aspects that surrounded an Albanian business, especially the culture of the Ferizaj area, in which individualism and control prevailed in every respect due to the high level of distrust.

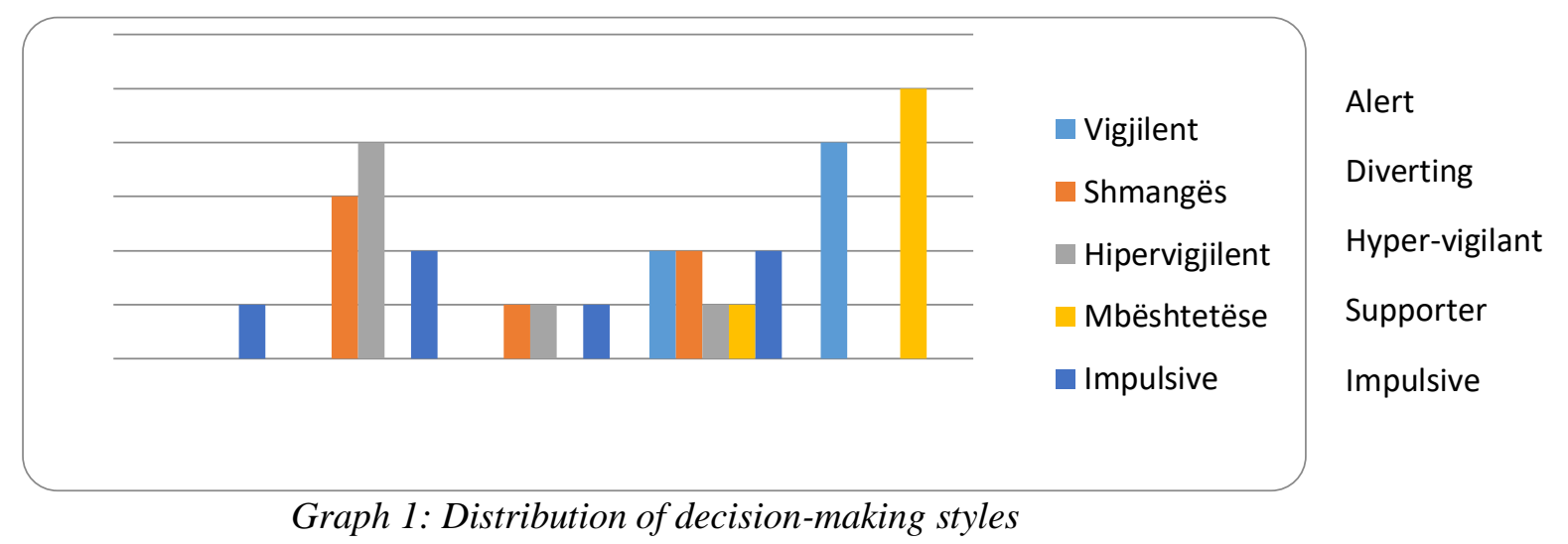

Source: SME Survey, Ferizaj, conducted by the author

During the analysis of the questionnaire, the hypothesis was rejected, due to the fact that a large number of respondents had a supportive style. That is, before making a decision they relied on the knowledge, advice and information of their peers, who according to them had the appropriate experience and information that would serve them for successful decision making. This can also be caused by the fact that we live in an uncertain environment in which it is impossible to know all the possible alternatives when analyzing a problem for a given decision.

So the hypothesis thrown on the fact that the dominant style in these companies is the observational style is down.

What can be noticed from the surveys is that in decision making, the most important dimensions for managers are: rational approach, focus on problems, desire for results and problem structuring.

\section{Study example}

Style relationships of decision making and the environment of the organization

The relationship between the decision making style of companies and the environment created by managers' perceptions has been studied through the evaluation of the correlation indicator. 
Table 1: Table of correlation between environment and decision making style.

\begin{tabular}{|c|c|c|c|c|c|c|}
\hline & Environment & Vigjilent & Diverting & Hypervigilant & Supporter & Impulsive \\
\hline Environment & 1 & & & & & \\
\hline Alert & -0.15309 & 1 & & & & \\
\hline Diverting & -0.343 & 0.140028 & 1 & & & \\
\hline Hypervigilant & -0.44227 & 0.111111 & 0.910182 & 1 & & \\
\hline Supporter & 0.954065 & -0.12632 & -0.45991 & -0.43511 & 1 & \\
\hline Impulsive & -0.53452 & -0.05455 & 0.870864 & 0.691023 & -0.71671 & 1 \\
\hline
\end{tabular}

\section{Source: SME Ferizaj Survey, author's elaboration}

As can be seen from the correlation table, decision making styles have a significant impact on the company environment. Decision-making styles such as alert style and supportive style are two of the styles that have the most significant impact on the environment.

The supportive style influences the improvement of the company environment and most strengthens the cooperation between managers $(r=0.954 ; \mathrm{p}<0.01)$. While other styles like, avoidant, hypervigilant and impulsive do not statistically reliably affect the company environment. To see the validity of the hypothesis, that is, to see if vigilance style has the most impact on the company environment, the statistical significance is noted. While referring to the ANOVA table we note that the statistician today has a value greater than the critical value of the statistician $t(t=1.878$ while $t$ stat $=1.7341$, hence $t>t$ stat). This means that the variable is statistically significant, so the hypothesis does not stand and falls down. So it is not the vigilant style that has the most significant impact on the company environment. We get the same result if we do a p-value analysis. 
Table 2: ANOVA 1

\begin{tabular}{|c|c|c|c|c|c|c|c|c|}
\hline ANOVA & & & & & & & & \\
\hline & Df & SS & MS & $\mathrm{F}$ & $\begin{array}{c}\text { Significance } \\
\text { F }\end{array}$ & & & \\
\hline Regression & 1 & 2.8125 & $\begin{array}{c}2.812 \\
5\end{array}$ & 0.072 & 0.80584 & & & \\
\hline Residual & 3 & 117.1875 & $\begin{array}{c}39.06 \\
25\end{array}$ & & & & & \\
\hline \multirow[t]{2}{*}{ Total } & 4 & 120 & & & & & & \\
\hline & Coefficients & $\begin{array}{c}\text { Standard } \\
\text { Error }\end{array}$ & $\mathrm{t}$ Stat & P-value & Lower 95\% & $\begin{array}{l}\text { Upper } \\
95 \%\end{array}$ & $\begin{array}{l}\text { Lower } \\
95.0 \%\end{array}$ & $\begin{array}{l}\text { Upper } \\
95.0 \%\end{array}$ \\
\hline Intercept & 6.563 & 3.494 & 1.878 & 0.157 & -4.557 & 17.682 & -4.557 & 17.682 \\
\hline Environment & -0.094 & 0.349 & -0.268 & 0.806 & -1.206 & 1.018 & -1.206 & 1.018 \\
\hline
\end{tabular}

Source: SME Survey, Ferizaj, conducted by the author

From the graph, during the descriptive analysis, it was noticed that one of the most prevalent styles was the supporting one and indeed, if we did the same study as above about the relation between the supporting style and the environment of the companies such a result is distinguished.

Table 3: ANOVA 2

\begin{tabular}{|l|l|}
\hline \multicolumn{2}{|l|}{ Regression Statistics } \\
\hline Multiple R & 0.954 \\
\hline R Square & 0.910 \\
\hline Adjusted R Square & 0.880 \\
\hline Standard Error & 3.75 \\
\hline Observations & 5 \\
\hline
\end{tabular}




\begin{tabular}{|c|c|c|c|c|c|c|c|c|}
\hline ANOVA & & & & & & & & \\
\hline & Df & SS & MS & $\mathrm{F}$ & $\begin{array}{c}\text { Significance } \\
\text { F }\end{array}$ & & & \\
\hline Regression & 1 & 427.813 & $\begin{array}{c}427.81 \\
3\end{array}$ & 30.422 & 0.012 & & & \\
\hline Residual & 3 & 42.188 & 14.063 & & & & & \\
\hline Total & 4 & 470.000 & & & & & & \\
\hline & Coefficients & $\begin{array}{c}\text { Standard } \\
\text { Error }\end{array}$ & t Stat & P-value & Lower 95\% & $\begin{array}{c}\text { Upper } \\
95 \%\end{array}$ & $\begin{array}{l}\text { Lower } \\
95.0 \%\end{array}$ & $\begin{array}{l}\text { Upper } \\
95.0 \%\end{array}$ \\
\hline Intercept & -0.938 & 2.096 & -0.447 & 0.685 & -7.609 & 5.734 & -7.609 & 5.734 \\
\hline Mjedisi & 1.156 & 0.210 & 5.516 & 0.012 & 0.489 & 1.823 & 0.489 & 1.823 \\
\hline
\end{tabular}

So managers are more encouraged to make a decision based on the advice and help of their peers. Here $\mathrm{t}=-0.447$ while $\mathrm{t}$ critical $=1.7341$, i.e. $\mathrm{t}<\mathrm{t}$ critical. The fact remains that the most prevalent style in the environment of these companies is the supporting style.

Hypothesis 2: There is a very close relationship between decision making style and company performance.

The managers / owners interviewed acknowledged that, at present, the intuitive approach is the dominant one in the decision-making of companies. However, managers share different opinions about the interdependence of company performance and decision making style. On this basis, regarding the use of the descriptive method, it was found that 33\% (about 59) of the interviewed managers accept the fact that the use of analytical methods results in better decision-making, affecting a higher performance of the company.

Whereas, $17 \%$ of managers think that business can have a different performance regardless of whether they use analytical methods or not in the decision making process. This group of managers relies on the fact that the success of the company is significantly conditioned by the matching of decision-making style with the problem posed for solution. 
When dealing with a problem previously experienced in the organizational context, an intuitive approach can be used very easily in this decision-making process. For the most part, about $50 \%$ (of 89 people) of managers interviewed admit that using the intuitive method of decision making can bring considerable success to the company. This group of managers point out that this is mainly the case for companies run by managers who have long-term experience in the field. According to them, the success that companies achieve when a manager uses intuitive methods in decision-making is attributed to the individual professional skills of the manager and his / her relatively long experience. This results from the method used in decision making.

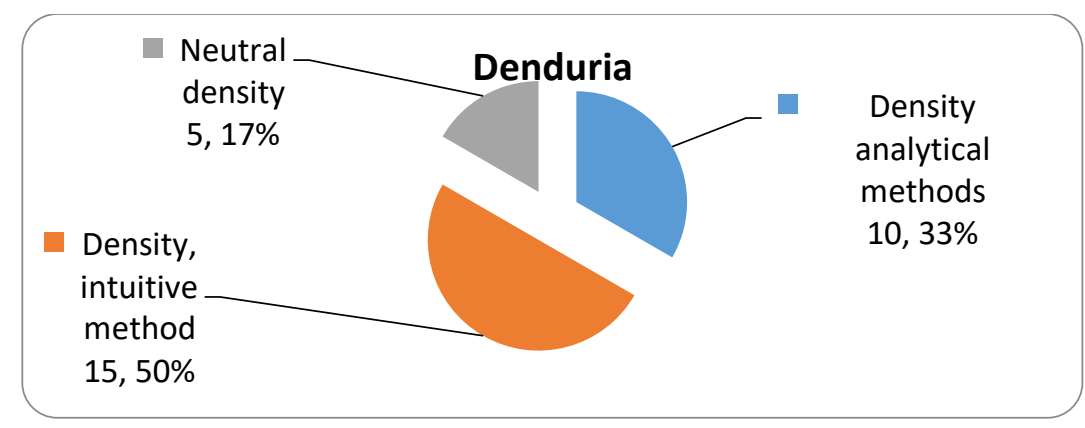

Graph 2: Distribution of decision making methods

Source: SME Survey, Ferizaj, conducted by the author

More specifically, in addition to the result derived from the analysis of the descriptive method discussed above, in the correlation study we claim the analysis of the reciprocal statistical relationships that was used.

\section{Statistical analysis}

In this part of the analysis, the use of some coefficients such as Pearson coefficient, t-statistic and Kendall coefficient are considered. Based on the aforementioned, analytical and intuitive methods as well as the data obtained from the managers' interviews, the following table was constructed having $r$ $=3$ lines and $\mathrm{c}=3$ columns:

Table 4. Use of analytical versus intuitive method in decision making

\begin{tabular}{|c|c|c|c|}
\hline Variables & Analytical methods & Intuitive method & Amount \\
\hline Less successful & $\mathrm{a}=8$ & $\mathrm{~b}=3$ & 11 \\
\hline More successful & $\mathrm{c}=4$ & $\mathrm{~d}=15$ & 19 \\
\hline Amount & 12 & 18 & 30 \\
\hline
\end{tabular}

Source: SME survey, Ferizaj, conducted by the author 
In this table we identify the true density for each combination of variables between the type of method used and the performance of the company. From this table we can calculate the coefficients as follows:

1. Julie Coefficient $\mathrm{Ka}=\frac{\mathrm{ad}-\mathrm{bc}}{\mathrm{ad}+\mathrm{bc}}$ where we have $\mathrm{Ka}=\frac{8 * 15-4 * 3}{8 * 15+4 * 3}=0.81$

2. Correlation Coefficient $\mathrm{Kl}=\sqrt{\frac{1-\frac{\mathrm{bc}}{\mathrm{ad}}}{1+\frac{\mathrm{bc}}{\mathrm{ad}}}}$ if the indicators are replaced we get this result $\mathrm{Kl} \sqrt{\frac{1-\frac{4 * 3}{8 * 15}}{1+\frac{4 * 3}{8 * 15}}}=$ 0.9

The coefficient of compliance, in both forms, highlights the fact that business performance is positively related, to a significant degree, to the method used in decision-making. This is quite good when compared to the standard coefficient of 0.707 . Given that $0.9>0.707$ and $0.81>0.707$ then we say that there is a significant relationship between the variables.

\section{Pearson coefficient}

As noted, we have two quality variables at two levels each. Pearson coefficient was used to identify the relationship between them. In this respect Michael J. Panik (2005) states: "The correlation calculated through the Pearson coefficient Qxy serves as an index of linear congruence between the two variables $\mathrm{x}$ and $\mathrm{y}$; it measures the power of the dependence of $\mathrm{x}$ and $\mathrm{y}$.

This coefficient is calculated as follows:

$C=\sqrt{\frac{x^{2}}{x^{2}+n}}$

For this we first compute the magnitude of $\mathrm{x}^{\wedge} 2$ by the following formula:

$\mathrm{x}^{2}=\frac{\sum(\mathrm{f}-\mathrm{fe}) 2}{\mathrm{fe}}$ religion where: $\mathrm{f}-$ factual density, fe-density

After successive substitutions, $x^{2}=7.89$ dhe $C=0.456$. And if we compare the Pearson coefficient with the critical coefficient, which has a value of 0.384 , we see that the Pearson coefficient has a value higher than the critical value. So $0.456>0.384$. So this is an indication that the hypothesis holds: There is a very close link between the method used (decision making style) and company performance. This is a strong argument that supports the idea that managers should orient their business of decision making in terms of using analytical methods. However, the use of analytical methods in the decision making of companies in the Ferizaj region was very small. When completing the questionnaire, managers were asked some questions about the methods they were using. The specific question was: 
Have the methods used in your company been successful? -Certainly a large part of them answered the question with an immediate YES. But the truth of this question was not limited to one YES. From various sources some of the financial statements of the last three years of some of the companies surveyed were found. These financial statements analyzed some items such as: the income, assets and expenses of these companies during this period. Interviewed managers who used the intuitive method and made up the bulk of this study acknowledged that the method used was a highly effective method and always had a positive impact on company profitability. But after analyzing the financial data of these companies it was quite clear that their profitability was good for the first 2 years, having fallen in the last year. This can come from a variety of factors such as new strategic decisions, new technologies, increasing available information, and so on.

The same analysis was done for the part of the companies whose managers used the analytical method. The analysis of the financial statements showed a steady gain (some small increases). So consequently they did not have any major losses. What stood out in the managers of these firms was the care and analysis they put into each option before making a decision.

\section{The use of intuitive method}

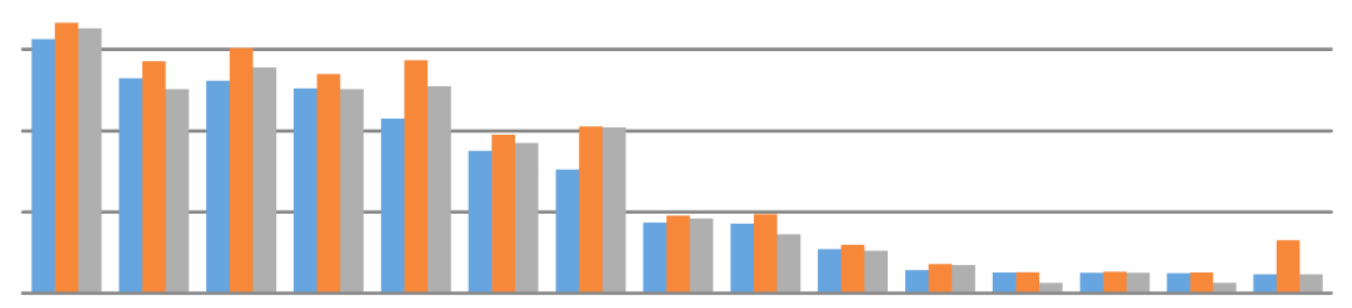

\section{7 profit 2018 profit 2019 profit}

Figure 3: Distribution of income for some of the companies using the intuitive method Source: SME Survey, Ferizaj, conducted by the author

During the interviews, there was also a handful of managers, about 17\%, who emphasized that they had been using the analytical method for some time, for about two years, and were now using the intuitive method. In analyzing the earnings of these companies it was seen that there was an increase in profit and a distinct factor was the age, where it was evident that younger managers were more inclined to use analytical methods and were more cautious in any decision made. Managers during the interview stated that in choosing the method to use they took into account a number of factors to consider: choice of management strategy, decision characteristics, environmental factors and firm characteristics. 


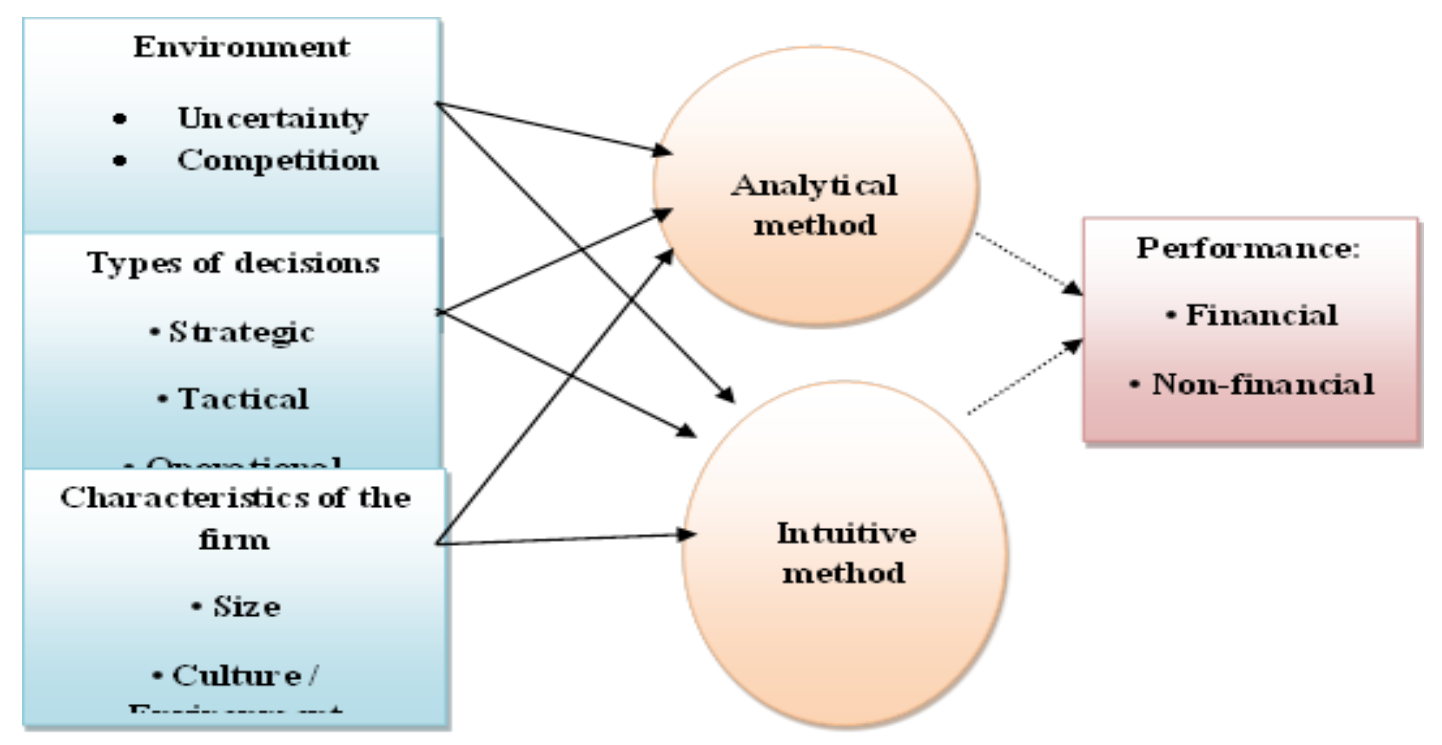

Figure 4: Table of influencing factors

Source: SME Survey, Ferizaj, conducted by the author

\section{Recommendations}

For example, vigilant style played a very important role in the company environment but was not the dominant one.

This style makes managers more cautious about different options for problem solving. Environmental characteristics influence several issues of the decision-making process.

Environmental characteristics have major consequences in all aspects of management, including strategies, structures, processes and outcomes.

Types of decisions we can have strategic, routine and operational decisions. In every company strategy we saw that we could use a different decision making method.

The characteristics of the firm, the larger the firm, the more important decisions have to be made and in these cases the best method to use is the analytical method.

Culture also plays an important role in choosing a decision-making method. 


\section{Reference list.}

[1]. Michael Armstrong 'Human Resource Menagement Practice' London 2006

[2]. Paul Banfield_Rebecca Kay Hyrje në menaxhimin e brimeve njerzore UET Press 2011

[3]. Scott, S. G. \& Bruce, R. A. (1995). Decision making style the development of a new measure. Educational and Psychological Measurement, 55 (5), 818-831

[4]. Oct 01, 1995 - Issue published: October 1, 1995 Susanne G. Scott. University of Colorado at Colorado

[5]. The Questionnaire of Decision Strategies developed by Kuzgun (1992)

[6]. https://research-methodology.net/impact-of-personality-and-decision-making-styles-onPeng M.W. (2009), 'Institutions, resources, and entry strategies in emerging economies. "Strategic Management Journal",

[7]. Kume, Vasilika, "Marrja e Vendimeve Manaxheriale”, Shtepia Botuese Pegi, 2010.

[8]. Leonard, Scholl, Kowalski (1999), Journal of Organizational Behavior, Volume 20, Issue 3, pages 407-420, May 1999

[9]. Vroom, Victor; Sternberg, Robert J. (2002). "Theoretical Letters: The person versus the situation in leadership". The Leadership Quarterly 13: 301-323Luman Porter dhe Edward Lawer

[10]. Wiener, Y. \& Vardi, Y. (1980). Relationships between job, organization, and career commitments and work outcomes- an integrative approach. Organizational Human Performance, 26

[11]. Weiner, Bernard (1980). Human Motivation: Metaphors, Theories, and Research. Lawrence Erlbaum Associates.

[12]. Vroom, Victor; Sternberg, Robert J. (2002). "Theoretical Letters: The person versus the situation in leadership". The Leadership Quarterly 13: 301-323Luman Porter dhe Edward Lawer

[13]. Wiener, Y. \& Vardi, Y. (1980). Relationships between job, organization, and career commitments and work outcomes- an integrative approach. Organizational Human Performance, 26

[14]. Weiner, Bernard (1980). Human Motivation: Metaphors, Theories, and Research. Lawrence Erlbaum Associates. 